\title{
Correction to: Current inverting metamutator, its implementation with a new single active device and applications
}

\author{
Elham Minayi ${ }^{1} \cdot$ I. Cem Göknar ${ }^{2}$
}

Published online: 3 September 2019

(C) Springer Science+Business Media, LLC, part of Springer Nature 2019

\section{Correction to: Analog Integrated Circuits and Signal Processing (2018) 97:15-25 https://doi.org/10.1007/s10470-018-1239-9}

Voltage Inverting Metamutator (VIM) and Current Inverting Metamutator (CIM) recently introduced in [1] were defined, respectively, with polarities shown in Fig. 1 and relations (1) and (2). However, a careful examination reveals that there is no difference between VIM and CIM of Fig. $1 \mathrm{~b}$ as changing the reference directions of $v_{n}$ and $i_{n}$ in VIM gives CIM as shown in Figs. $1 \mathrm{~b}$ and 2. So the 4-ports in Fig. 1a, b are the same.

The CIM as given by Fig. 2, with the same reference directions as those of VIM, and defining relation (2) is an entirely different 4-port. In fact, their circuit level realizations are respectively given in Fig. 3a, b. $\left[\begin{array}{c}i_{k} \\ i_{l} \\ v_{m} \\ v_{n}\end{array}\right]=\left[\begin{array}{llll}1 & 0 & 0 & 0 \\ 0 & 1 & 0 & 0 \\ 0 & 0 & 1 & 0 \\ 0 & 0 & 0 & 1\end{array}\right]\left[\begin{array}{c}i_{m} \\ i_{n} \\ v_{l} \\ -v_{k}\end{array}\right]$

$$
\left[\begin{array}{c}
i_{k} \\
i_{l} \\
v_{m} \\
v_{n}
\end{array}\right]=\left[\begin{array}{llll}
1 & 0 & 0 & 0 \\
0 & 1 & 0 & 0 \\
0 & 0 & 1 & 0 \\
0 & 0 & 0 & 1
\end{array}\right]\left[\begin{array}{c}
i_{m} \\
-i_{n} \\
v_{l} \\
v_{k}
\end{array}\right]
$$

Everything else in [1], including realizations of CIM with IC blocks, remains unaltered.

The original article can be found online at https:// doi.org/10.1007/s10470-018-1239-9.

I. Cem Göknar

cem.goknar@isikun.edu.tr

Elham Minayi

eminayi@dogus.edu.tr

1 ECE Department, Doğuş University, Acıbadem 34722, Istanbul, Turkey

2 EE Department, Işık University, Şile 34980, Istanbul, Turkey 


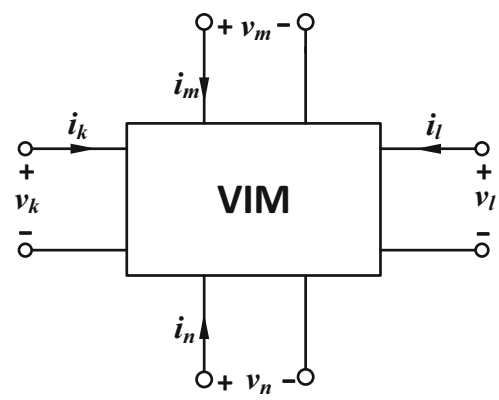

(a)

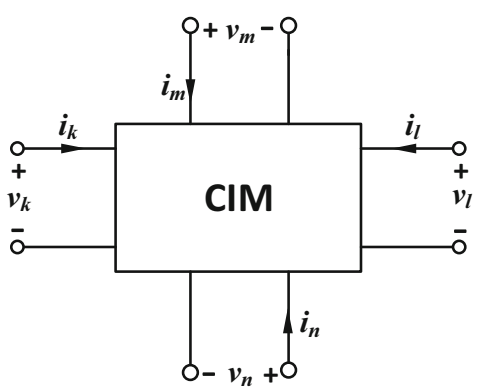

(b)

Fig. 1 a Block diagram of VIM, $\mathbf{b}$ wrong block diagram of CIM in [1]

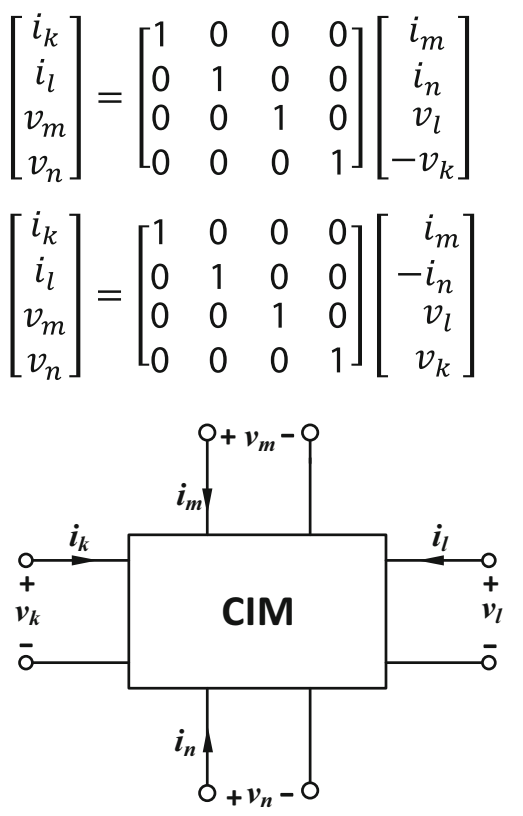

Fig. 2 Correct block diagram of CIM

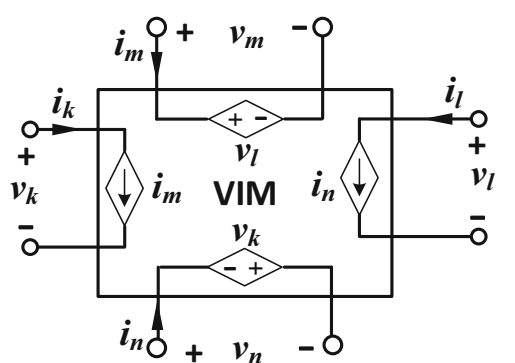

(a)

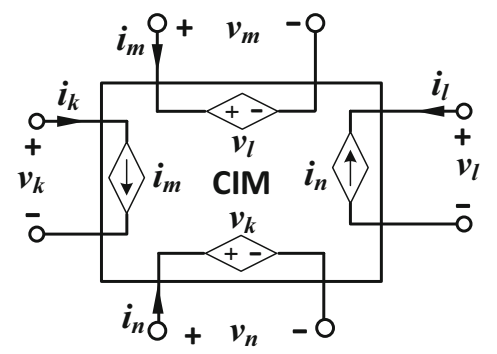

(b)

Fig. 3 Circuit level realization of a VIM, b CIM

\section{Reference}

1. Minayi, E., \& Göknar, İ. C. (2018). Current inverting metamutator, its implementation with a new single active device and applications. Analog Integrated Circuits and Signal Processing, 97(1), 15-25. https://doi.org/10.1007/s10470-018-1239-9.

Publisher's Note Springer Nature remains neutral with regard to jurisdictional claims in published maps and institutional affiliations.

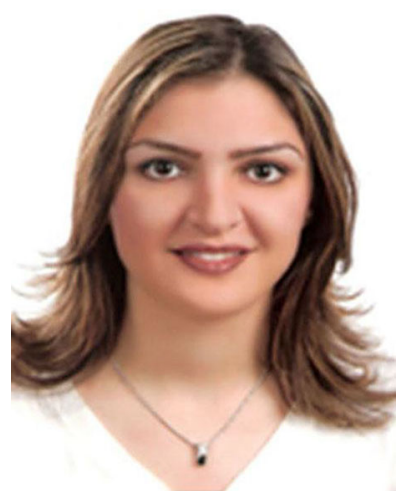

Elham Minayi received the B.Sc. degree in Electrical and Electronics Engineering from Islamic Azad University Central Tehran Branch, Tehran, Iran, in 2004. She obtained her M.Sc. degree in 2014 from the Electronics and Communications Engineering Department of Dogus University, Istanbul, Turkey, and currently is a Research Assistant at the same department having completed successfully her Ph.D. Thesis defense. Her research interests include memristor and memristive devices. 


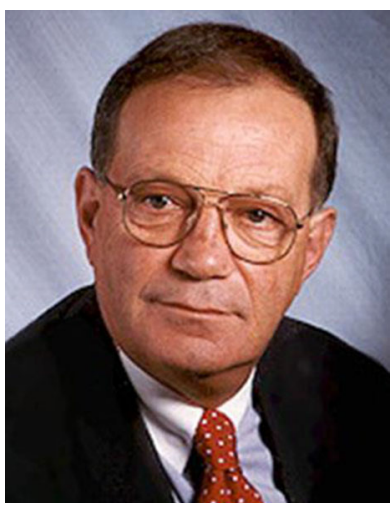

I. Cem Göknar received the Dipl. Ing. degree in $\mathrm{EE}$ from Istanbul Technical University (ITU), Istanbul, Turkey, the Ph.D. degree from Michigan State University, East Lansing in 1963 and 1969, respectively. He joined ITU in 1963 and became Full Professor in 1979. He received the Minna-James Heineman-Stiftung Grant under NATO's Senior Scientist Program and was a Visiting Professor with the University of California, Berkeley, in 1977, the University of Waterloo, Waterloo, ON, Canada, in 1978, the
Technical University of Denmark, Lyngby, Denmark, in 1980 and the University of Illinois at Urbana-Champaign, from 1995 to 1998. Currently he is a Professor at the EE Department of Işık University and was the Electronics and Communications Engineering Department Founding Head, at Dogus University, Istanbul, Turkey between 2000 and 2015. He has published more than 140 technical papers. His current research interests include circuits and systems, signal processing, neural networks, chaos, and fault diagnosis. Dr. Göknar is a Life Fellow of IEEE, IEEE-TR CASS Chapter Chair, a member of the Scientific Committee of European Conference on Circuit Theory and Design, European Circuit Society Council, and Turkish Electrical Engineers Chamber. 